\title{
Correction to: Effects of Dendrimer-Like Biopolymers on Physical Stability of Amorphous Solid Dispersions and Drug Permeability Across Caco-2 Cell Monolayers
}

\author{
Monika Lavan ${ }^{1}$ and Gregory Knipp ${ }^{1,2}$
}

Published online 28 June 2018

Correction to: AAPS PharmSciTech

https://doi.org/10.1208/s12249-018-1080-6

During the production process, an editorial error occurred where the label numbering for the first two tables were inadvertently switched. The original article has been corrected.

The online version of the original article can be found at https:// doi.org/10.1208/s12249-018-1080-6

\footnotetext{
${ }^{1}$ Department of Industrial and Physical Pharmacy, College of Pharmacy, Purdue University, 575 Stadium Mall Drive, West Lafayette, Indiana 47907-2091, USA.

${ }^{2}$ To whom correspondence should be addressed. (e-mail: gknipp@purdue.edu)
} 